\title{
A SAÚde NA PóS-MODERNIDAde
}

\author{
THE HEALTH IN THE POST MODERNITY
}

Germano André D. Schwartz $\left(^{(*)}\right.$

\section{RESUMO}

Este artigo pretende demonstrar a influência da pós-modernidade na saúde e suas conseqüências na proteção do direito à saúde.

\section{Palavras-chave}

Direito à saúde, Pós-modernidade, Risco.

\section{ABSTRACT}

This article intends to show the post modernity influence in health and its consequences in the protection of the right to the health.

\section{Keywords}

Right to the Health, Post Modernity, Risk.

\section{A PÓS-MODERNIDADE e A SAÚdE}

O conceito de saúde é um conceito complexo ${ }^{(1)}$ - uma vez que a saúde se encontra inserida na pós-modernidade - e que somente pode ser

(*) Doutorando em Direito pela UNISINOS - Universidade do Vale do Rio dos Sinos. Mestre em Direito pela UNISC - Universidade de Santa Cruz do Sul. Professor da UPF - Universidade de Passo Fundo e da ULBRA - Carazinho. Autor da obra Direito à Saúde: efetivação em uma perspectiva sistêmica. Porto Alegre: Livraria do Advogado, 2001, 224p.

(1) Para tanto, utilizamo-nos do conceito sistêmico de saúde por nós proposto em SCHWARTZ, Germano André Doederlein. Direito à Saúde: efetivação em uma perspectiva sistêmica. Porto Alegre: Livraria do Advogado, 2001, p. 43. "A saúde, para efeitos de aplicação do art. 196 da CF/88, pode ser conceituada como um processo sistêmico que objetiva a prevenção e cura de doenças, ao mesmo tempo em que visa à melhor qualidade de vida possível, tendo como instrumento de aferi- 
descrito por meio de uma teoria também complexa: a teoria dos sistemas, visto que a saúde é um processo em constante evolução/mutação.

A velocidade com que os procedimentos científicos inerentes à saúde, bem como a rápida propagação e/ou surgimento de doenças, surgem coloca por terra qualquer pretensão de uma solução única para o problema sanitário, complicando ainda mais o que já era complexo por natureza.

Muito embora haja alguma discordância na doutrina quanto à denominação (pós-modernidade e/ou modernidade da modernidade) e/ou o corte exato do nascimento dessa época, em face da descontinuidade(2) de tal período, o fato é que nos encontramos em um momento ímpar, devido, principalmente, às mudanças ocorridas na sociedade nos últimos quatro séculos.

É assim que a irresistível velocidade dos processos sociais aparece, então, como o reverso de uma cultura saturada, em estado de cristalização ${ }^{(3)}$.

Essas mudanças são de tal forma rompedoras de paradigmas que 0 homem se vê prostrado diante da transformação de um mundo relativamente simples para um deveras complexo, de onde ele não pode se evadir ou se furtar de participar. O conhecimento humano demonstra-se possível de captar apenas parte da totalidade, deixando o indivíduo imerso em incertezas e minando a pretendida racionalidade weberiana.

\section{A NECESSÁRIA AUTO-OBSERVAÇÃO}

Assim, a pós-modernidade apresenta-se como uma sociedade por demais complexa. Torna-se mister adotar uma teoria que abrande tal complexidade inerente às sociedades modernas e que relativize o ponto de vista distanciado do observador pós-moderno(4).

Esse é o fulcro da teoria dos sistemas. $E$ isso é feito a partir de uma idéia de observação autoconstitutiva. Ou seja, uma meta-observação de segundo grau, em que o observador está inserido e ao mesmo tempo é um outsider em relação ao sistema. Dessa forma poderá haver organização e reflexividade em torno do sistema.

ção a realidade de cada individuo e pressuposto de efetivação a possibilidade de esse mesmo individuo ter acesso aos meios indispensáveis ao seu particular estado de bem-estar".

(2) Cf. GIDDENS, Anthony. As Conseqüências da Modernidade. Tradução de Raul Filker. 5a reimpresssão. São Paulo: Editora UNESP, 1991, 177p.

(3) HABERMAS, Jürgen. O Discurso Filosófico da Modernidade. São Paulo: Martins Fontes, 2000, p. 6 .

(4) HABERMAS, Jürgen, ibidem, p. 6. 
Como assinala De Giorgi:

"A observação da contínua autoconstituição do presente, a sua manifestação como espaço da simultaneidade universal do operar dos sistemas permite isolar a teoria como a auto-reflexão deste operar. A auto-referência é, a um só tempo, princípio de organização e de reflexão. A teoria está dentro e fora ao mesmo tempo"(5).

A auto-observação da complexidade é, em outras palavras, referir que sempre haverá mais possibilidades do que se possa realizar. Ou seja, somente se escolhe (seleciona) uma decisão porque há a alternativa implícita ou explícita da possibilidade de uma seleção diversa. Logo, tal complexidade, inclusive no campo sanitário, é conceituada como a totalidade das possibilidades de experiências ou ações, cuja ativação permita o estabelecimento de uma relação de sentido(6).

Essa ativação consiste no fato de se pressupor que a opção por uma alternativa tem como necessária decorrência a não tomada de alternativa contrária ou diferente. Isso significa que no direito, ao existir uma norma, devemos analisar também não somente o que é permitido, mas sim o que foi proibido.

\section{A SELETIVIDADE SANITÁRIA}

Por outro lado, mesmo que todas as possibilidades do sistema-saúde fossem exaustivamente descritas e analisadas - idéia central do fracassado Projeto Genoma - inexistiriam garantias de que tais possibilidades viessem a ocorrer no mundo dos fatos. Esse fenômeno é a denominada contingência, isto é, o fato de que as possibilidades apontadas para as demais experiências poderiam ser diferentes das esperadas ${ }^{(7)}$.

Portanto, o espaço da modernidade é o espaço da artificialidade. É nesse espaço que surgem os potenciais da liberdade do agir dentro da concepção dos sistemas sociais. São potenciais vinculados à cognição via comunicação. Trata-se de construir alternativas por intermédio de uma decisão contingente recuperada pelo valor positivo da possibilidade que nega o valor negativo da condenação( ${ }^{(8)}$.

Em outras palavras: complexidade é seletividade forçada. A contingência tem como intrínseca a possibilidade de desapontamento. Logo, abar-

(5) DE GIORGI, Rafaelle. Direito, Democracia e Risco : vínculos com o futuro. Porto Alegre: SAFE, 1998, p. 22.

(6) LUHMANN, Niklas. Sociologia do Direito I. Rio de Janeiro: Tempo Brasileiro, 1983, p. 12.

(7) Ibidem, p. 45.

(8) DE GIORGI, Rafaelle, op. cit., p. 22. 
car a figura do risco torna-se mister para a tentativa de compreensão das decisões no mundo pós-moderno e, principalmente, na área da saúde.

\section{O CONTROLE DO TEMPO EM SAÚDE}

O fato de a saúde ser um sistema aberto e operativo faz com que o intercâmbio de influências e de comunicação de tal sistema com os demais gere uma contingência excessiva a respeito, devido à diferenciação resultante de dita autopoiese, o que leva a uma crescente criação de sistemas e subsistemas, todos eles com características e estruturas intrínsecas próprias, tendentes a decisões sobre suas especificidades. nala De Giorgi:

É, portanto, o risco uma condição estrutural da auto-reprodução. Assi-

"Nos sistemas diferenciados da sociedade moderna, o risco é condição estrutural da auto-reprodução; de fato o fechamento operativo dos sistemas singulares determinados pelas estruturas e unidos estreitamente torna possivel o controle do ambiente, ou seja, torna improvável a racionalidade e por isto constrange os sistemas a operar em condições de incerteza"(9).

Isso faz com que o risco esteja potencializado - tanto no mundo da vida como no dos sistemas (principalmente o sanitário) - forçado pela dupla contingência do mundo social: só posso reconhecer minhas expectativas através das expectativas de um outro. Só posso decidir de uma maneira porque poderia tomar uma decisão diversa(10).

Todavia, a fim de que a indeterminação alcance um ponto em que a psique do homem não suporte essa expectativa de expectativa, o direito torna-se um mecanismo redutor de complexidade, em que a norma (e no caso da esfera pública sanitária: decisões) serve para orientar o indivíduo, trazendo consigo mesma a possibilidade do risco, dispensando a orientação a partir de expectativas, e, logo, reduzindo a probabilidade de dano futuro (risco). É nessa medida que a regra alivia a consciência no contexto da complexidade e da contingência ${ }^{(11)}$.

Assim, a estrutura do direito moderno rompe com a antiga unidade entre validade e fundamento. Validade é um símbolo que circula nos sistemas e que vincula a contingência dos valores à autofundamentação da

(9) DE GIORGI, Rafaelle, op. cit., p. 197.

(10) Com maior especificidade, sugere-se a leitura de nossa obra Direito a Saúde..., cit., pp. 88 e segs.

(11) LUHMANN, Niklas. Sociologia do Direito I, cit., p. 53. 
normatividade $^{(12)}$. É, pois, a contigência uma garantia de que se pode dotar o sistema do direito voltado para o futuro.

Essa atitude é uma atitude de encarar um desafio. De tentar verificar, sem saber se haverá sucesso, se a autoreferência da sociedade conduzirá a sociedade a um melhor termo.

Recorda Habermas:

"As condições da vida moderna, que nós não escolhemos por nós mesmos, e sob as quais nos encontramos, são inevitáveis do ponto de vista existencial; mesmo assim, aos olhos despertos da modernidade, elas significam um desafio a mais, não uma simples fatalidade"(13).

A resposta da sociedade organizada é agir preventivamente em relação a uma expectativa de futuro. Portanto, a questão é uma imunização contra prováveis decepções. Em outras palavras: tentar prever o futuro tendo

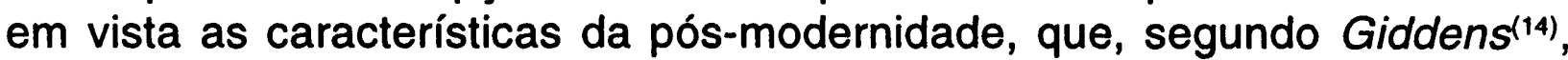
são: (a) separação de espaço e tempo; (b) o desencaixe dos sistemas sociais $^{(15)}$; e (c) a ordem e desordem reflexiva das relações sociais.

\section{O RISCO E A (IN)CERTEZA NA SAÚDE}

Baseado no passado, todos os sistemas (como é o caso da saúde) visam à antecipação do futuro com base no risco. Dessarte, o risco

"é modalidade secularizada de construção do futuro. Já que torna plausível pontos de vista diferentes da racionalidade, na condição de que estes sejam capazes de rever os próprios pressupostos operativos e na condição de que, há tempo para efetuar esta revisão, esta perspectiva é típica da sociedade moderna"(16).

Aqui se assinala que a norma/decisão tem uma função de controle de tempo se utilizando de uma programação condicional para decisões(17). Dita programação condicional vem a ser a norma jurídica, uma norma de comportamento garantida de modo contrafático assim como as decisões relativas à questão da saúde. Como lembra Giddens, o caráter contrafatual da

(12) DE GIORGI, Rafaelle, op. cit., p. 29.

(13) HABERMAS, Jürgen. Passado como Futuro. Rio de Janeiro: Tempo Brasileiro, 1993, p. 92.

(14) Apud BRÜSEKE, Franz Josef. A Técnica e os Riscos da Modernidade. Florianópolis: Editora da UFSC, 2001, p. 19.

(15) Em termos sistêmicos, seria melhor adotar o termo "instabilidade dos sistemas".

(16) DE GIORGI, Rafaelle, op. cit., p. 198.

(17) Para maiores detalhes, consultar ROCHA, Leonel Severo. "Teoria do Direito e Transnacionalização". Revista do Direito/Universidade de Santa Cruz do Sul, n. 9-10, jan./dez. 1998(b), pp. 7-14. 
maior parte dos riscos conseqüentes está intimamente vinculado à insensibilidade que uma listagem deles tende a promover ${ }^{(18)}$.

Logo, sob outro prisma, o Direito e o Estado do final do séc. XX estão em quadro marcado pela solidão, isolamento, diferença e separação, uma vez analisados/observados por teorias incompativeis com sua complexidade e ligados a tempos idos.

"Vimos séculos de trevas, séculos iluminados, séculos dos princípios e do romantismo de uma razão que afirmava a liberdade das singularidades enquanto refletia na poesia a desilusão do seu fechamento e do seu isolamento. Este último, o século que está por terminar, é o século dos ocasos... Este século foi caracterizado como a era dos direitos. O século anterior realizara os pressupostos iluministas do direito igual, contribuíra para a superação dos privilégios, bem como reconhecera a liberdade dos indivíduos mediante a prática do contrato, a constitucionalização do acesso universal ao direito e à livre circulação da propriedade. Neste século foram afirmadas as individualidades dos indivíduos que levaram à necessidade de se reconhecer, como já dizia Max Weber, elementos materiais na racionalidade formal do direito"(19).

Assim, o século (tempo) atual é resultado de um paradoxo constitutivo que está vinculado a um paradoxo temporal. Ora, Estado e Direito sempre foram tratados, com referência ao pensamento do direito natural, como resultado da diferença entre eternidade e temporalidade.

\section{CONSIDERAÇÕES FINAIS}

Hodiernamente, Direito e Estado - e não importa sob que forma de sua apreensão - são representações de ordem voltados para o futuro. São construções e resultados de construções. São também esboços do futuro. Em suas representações, há uma representação do futuro.

É por isso que o projeto pós-moderno é um projeto único e ligado ao risco como qualquer projeto grandioso e ambicioso. $A$ modernidade não pode e não quer tomar dos modelos de outra época os seus critérios de orientação, ela tem de extrair de si mesmo a sua normatividade ${ }^{(20)}$.

$\mathrm{Na}$ estrutura auto-reflexiva de estabilização dos sistemas, mediante programação contrafática tendente ao futuro, é que o risco se apresenta não como tormento, mas sim como alívio de uma expectativa negativa.

(18) GIDDENS, Anthony, op. cit., p. 135.

(19) DE GIORGI, Rafaelle, op. cit., p. 71.

(20) HABERMAS, Jürgen, O Discurso Filosófico..., cit., p. 12. 
Concordando com De Giorg(21), o risco é uma aquisição evolutiva do tratamento das contingências e sua construção de vínculos do futuro reside na dicotomia probabilidade/improbabilidade. Mas, o risco está ligado a uma forma negativa (bad) e não ao bom (good).

Ressalte-se que, na busca do alívio de expectativas, o sistema jurídico utiliza uma programação condicional, fundada em seus elementos estruturantes, mormente na norma jurídica, pois em caso contrário não estaria reduzindo complexidade.

Da mesma forma, as organizações componentes do sistema-saúde em que se inclui a gestão compartida - têm como função uma decisão relativa à atividade sanitária, quer seja ela de cunho prevencionista, quer seja de característica promocional, ou, ainda, uma necessidade de cura.

O sistema jurídico interage com o sistema-saúde quando este tem seu ato decisório desrespeitado e/ou não efetivado (e vice-versa), momento em que, devido ao inevitável processo de comunicação dos sistemas, as regras jurídicas controladoras do tempo sanitário serão analisadas no fórum adequado e que possui legitimação(22) para tanto - o sistema jurídico -, a quem caberá proferir decisão sobre o tema.

Portanto, sempre haverá ato decisório em cada um dos sistemas sociais. Essa decisão será gravada de risco, inevitavelmente, visto que este é um evento generalizado da comunicação(23).

Daí surge o paradoxo existente entre comunicação e diferenciação: mesmo que possua condições de combater as indeterminações, a sociedade moderna não pára de produzi-las. $E$, mais paradoxalmente ainda, é esta indeterminação que combate a repetição interior do sistema, tornando provável o improvável e garantindo a evolução dos mesmos.

A saúde é uma atividade em que o risco é onipresente. Assim, por exemplo, o ato de um cidadão usar ou não preservativo em um ato sexual extraconjugal é um ato decisório, cujo risco reside, basicamente, em possíveis danos futuros à sua saúde e de seus parceiros, mas que é avaliado em seu presente com base em seu conhecimento passado.

Seguindo na esteira de que toda decisão deve ser avaliada do ponto de vista do observador, uma vez que se poderá chegar a conclusões díspa-

(21) DE GIORGI, Rafaelle, op. cit., p. 198.

(22) Cf. LUHMANN, Niklas. Legitimação pelo Procedimento. Brasília: Editora UnB, 1980.

(23) Assim como propõe ROCHA, Leonel Severo. Epistemologia Juridica e Democracia. São Leopol-

do: Unisinos, 1998(a), p. 99. 
res, assinala De Giorgi a respeito - especificamente na possibilidade de contágio de AIDS por via sexual:

"Aqui é necessário distinguir dois aspectos: por um lado trata-se da disponibilidade ao risco de parte daqueles que estão imediatamente interessados em contatos sexuais e que, portanto, o buscam; do outro trata-se da implicação dos sócios destas pessoas que vivem de modo duradouro. Para aquele que busca a aventura sexual é um risco que ele valoriza de maneira mais ou menos alta, sejam quais forem os motivos. Para o outro é um perigo"(24).

Em outro ângulo, os planos de saúde não podem dar garantias mediante cláusulas de que um evento não ocorra. Eles somente asseguram que quando haja o dano causado pelo risco, este seja minimizado. Para Luhmann, todo o possivel deve ser feito para minimizar o risco sanitário. Logo, a gestão compartida sanitária é mais um elemento redutor de complexidade nesse sentido, visto que o risco em saúde reside no "riesgo de hacer algo que posiblemente podría ayudar. Sería incomprensible, incluso indenfendible, no intentar todo lo posible aúnque solo pueda tratarse de otra distribución del riesgo"(25).

Adquirindo tal consciência, as modernas correntes doutrinárias de saúde começam a adotar a idéia do enfoque de risco(26).

Portanto, o risco em saúde está ligado a uma idéia contrária de segurança: está ligado ao perigo. Toma particular relevância ligar o risco sanitário à questão democrática, uma vez que uma verdade única leva a um inevitável totalitarismo, característica de sociedades que não podem se intitular como modernas, e algo que deve ser combatido em uma visão gestora compartida de saúde, que proporcione um alívio de expectativas negativas mediante um processo deliberativo formador de consenso entre falas díspares e que requerem uma mudança estrutural em uma nova esfera pública sanitária.

\section{BIBLIOGRAFIA}

BRÜSEKE, Franz Josef. A Técnica e os Riscos da Modernidade. Florianópolis: Editora da UFSC, 2001.

DE GIORGI, Rafaelle. Direito, Democracia e Risco: vínculos com o futuro. Porto Alegre: SAFE, 1998.

(24) DE GIORGI, Rafaelle, op. cit., p. 241.

(25) LUHMANN, Niklas. Observaciones de la Modernidad. Barcelona: Ediciones Paidós lbérica, 1997, p. 137.

(26) Cf. PARRA, Antonio Yepes. "EI Derecho a la Salud. La Necesidad de Repensar los Derechos Sociales". Revista Cubana de Salud Pública, n. 25(2), 1999, pp. 112-122. 
GIDDENS, Anthony. As Conseqüências da Modernidade. Tradução de Raul Fiker. 5ª reimpressão. São Paulo: Editora UNESP, 1991.

HABERMAS, Jürgen. Passado como Futuro. Rio de Janeiro: Tempo Brasileiro, 1993.

Fontes, 2000.

O Discurso Filosófico da Modernidade. São Paulo: Martins

LUHMANN, Niklas. Legitimação pelo Procedimento. Brasília: Editora da UnB, 1980. . Sociologia do Direito I e II. Rio de Janeiro: Tempo Brasileiro, 1983.

. Observaciones de la Modernidad. Barcelona: Ediciones Paidós Ibérica, 1997.

PARRA, Antonio Yepes. "EI Derecho a la Salud. La Necesidad de Repensar los Derechos Sociales". Revista Cubana de Salud Pública, n. 25(2), 1999.

ROCHA, Leonel Severo. Epistemologia Jurídica e Democracia. São Lieopoldo: Unisinos, 1998(a).

. "Teoria do Direito e Transnacionalização". Revista do Direito/ Universidade de Santa Cruz do Sul, n. 9-10, jan./dez. 1998(b).

SCHWARTZ, Germano André Doederlein. Direito à Saúde: efetivação em uma perspectiva sistêmica. Porto Alegre: Livraria do Advogado, 2001. 